Reig, O. A., and Sonnenschein, C. (1970): The chromosomes of Marmosa fuscata Thomas, from Northern Venezuela (Marsupialia, Didelphidae). Experientia 26, 199-201.

Segall, W. (1969): The middle ear region of Dromiciops. Acta anat. 72, 489-501.

Spotorno, A., and Fernandez, R. (1971): The chromosomes of the "monito del monte" Dromiciops australis Philippi. Mamm. Chrom. Newsletter 14, 40-41.

Tate, G. H. H. (1933): A systematic revision of the marsupial genus Marmosa. Bull. Amer. Mus. Nat. Hist. 66, $1-250$.

Addresses of the authors: Osvaldo A. ReIG, Department of Zoology, University College London, Gower Street, London WC 1, England; RAúl FernándeZ D. and Angel Spotorno O., Laboratorio de Citogenética, Departamento de Genética, Universidad de Chile, Calle Zañartu 1042, Santiago, Chile

\title{
Biology of the Rice Rat (Oryzomys palustris natator) in a Laboratory Environment
}

\author{
By A. Wallace Park and B. J. A. Nowosielski-Slepowron \\ Departments of Dental Surgery and Biological Sciences \\ University of Dundee
}

Receipt of Ms. 11. 10. 1971

\section{Introduction}

Within the genus Oryzomys, over 100 species have been described and the extent of their habitat is shown by their presence in most of South America, Central America and Mexico with extensions to East Kansas, southern Illinois und New Jersey.

The original vernacular name "rice meadow mouse" stemmed from the work of Audubon and Bachmann (1854) and was given to Oryzomys palustris because it was observed in the rice fields of South Carolina and Georgia. This nomenclature has inevitably resulted in the appellation "rice rat" being applied to all the species even though their habitat covers marshy areas along the coasts to the extremes of brush in the mountains and grassy areas in the mesquite brush. This inclusion of the species with widely differing habitats and behaviour under one genus is regarded by Goldman (1918) as having originated due to the similarity in ratlike form and general appearance. Thus the genus comprises of a mixed assemblage of species with wide diversity of general characters - the whole being lightly fused together by the similarities exhibited by the molar cusp pattern.

Historical confusion of nomenclature when based on limited observations is often unavoidable, and after the first species of Oryzomys had been described under the name of Mus palustris from New Jersey by Harlan (1837), then Audubon and Bachman (1854) erroneously placed it under the genus Arvicola. The full generic name for the group - Oryzomys - was finally introduced by BAIRD (1857) with Mus palustris (Harlan) as the type species. Unfortunately, the story did not end at this point because BAIRD recorded it on a later page of his publication with a 
subgeneric rank - Hesperomys of Waterhouse. This was accepted by Couns and Elliott (1877) and remained unchanged for some 13 years at which time Coues and Elliott (1890) established its full generic ranking.

A synopsis of the North American rice rats was published by Merriam (1901) and this was followed by descriptions of new species by Thomas (1901), Bangs (1902), Elliott (1903, 1904), Allen (1908) and Goldman (1912, 1913, 1915, 1918). A review of the characteristics of the genus Oryzomys was undertaken by ElLERman (1941).

The particular member of the rice rat group which this paper covers is Oryzomys palustris natator (CHAPMAN) which was annexed from the wild state for experimental purposes. The assimilation of this rat into a laboratory environment was first attempted by STEWARD in 1949 in order to test its suitability in the routine screening of antifilarial compounds. In 1951 a short statement was made that the rat did not appear to be suitable as a host for the filariid worm Litomosoides.

A small colony was introduced to the Harvard School of Dental Medicine in 1952 and consisted of 15 pairs which eventually gave rise to a F-1 generation stemming from 11 of the females and 12 of the males. This stock over the next few years had to be continually supplemented by weanlings obtained from elsewhere resulting in a dearth of information regarding identification, age and breeding details. A decision was made to establish a Harvard colony in 1956 and the Dundee colony was instituted in 1967 by the arrival of a small breeding nucleus of rice rats from the Harvard group.

Present knowledge of the development and growth in the widely distributed and ecologically versatile rodent genus Oryzomys is limited, in most instances, to a number of references to the taxonomy, distribution, ecology and habits. The rice rat Oryzomys palustris natator is one of those of which little has been written on the biological aspects. Work by Hamilton (1946) on the habits of the type species Oryzomys palustris palustris was followed by GuPTA and SHAw (1956) with an account of the anatomy of the teeth and times of eruption of $O$. palustris natator.

\section{Material and Methods}

\section{The Colony}

The original wild stock was trapped near Sarasota in Florida and identified as Oryzomys palustris natator. The main Harvard colony was established in 1956 after a pilot attempt in 1952. The breeding policy was to mate stock on a monogamous basis at weaning and the same male and female kept together throughout their breeding lives. Prior to the establishment of a daughter colony in Dundee in 1967, the Harvard group had reached their 15th generation in laboratory environment.

A total of 9 pairs of rice rats were used to set up the Dundee colony and of these 3 males and 4 females failed to breed. In addition, five of the rats with offspring were sent to establish daughter colonies in London and Copenhagen leaving the building of the colony in Dundee to rely on the proven breeding capacity of 3 males and 3 females. After a poor start, the colony increased its numbers so that by 1969 there were some 260 rats in the laboratory.

\section{Management}

The rice rats were kept in ordinary wire rat cages $(44 \times 28 \times 12 \mathrm{cms})$ bedding consisting of a fine gravel and nesting material was supplied in the form of a thick cleansing paper which was eventually weaved into nests.

During pregnancy the male was generally removed although there was no definite proof that his presence triggered off cannibalism - both sexes have been known to reduce the 
number of young in the cages. As a general rule, if the young rats lasted the first six to seven days, their chances of survival appeared to be high.

The food supplied was of a standard type known as Rat Cake Diet 86 (North Eastern Farmers Ltd., Bannermill, Aberdeen, Scotland) and consisted of the following ingredients:

Diet 86

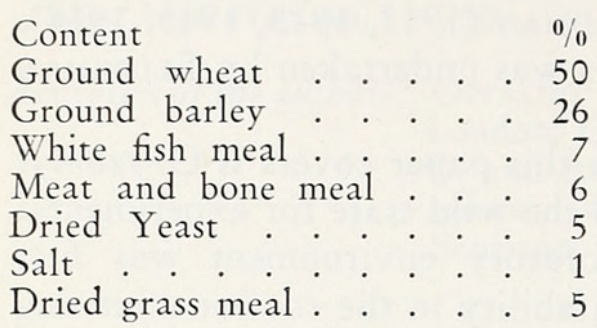

Plus: Vitamin supplement which supplies

8 million I. Us. Vitamin A and

2 million I. Us. Vitamin D3 per ton.

Water was continuously available in standard drinking bottles.

\section{Data}

This was collected from the colony during two separate examinations with a period of one year between. In these the weight, sex and age were found. Further more detailed observations were made on some 250 rats ranging in age from birth to 16 months, the main interest being the development of the young. Included in the data were gestation periods, litter size, morphological development and longevity. Linear measurements were found by means of a Western Reserve Measuring board (Acheson, MacIntyre and Oldham 1959) after the rats had been killed by an overdose of ether. Each rat was weighed during the census of the colony and after the rats had been killed. The results were recorded in grams and taken to one decimal place. In the younger rats the age was assessed as being taken arbitrarily, at birth, as occurring at $1.00 \mathrm{am}$., unless there were indications of a very recent birth upon which adjustments were accordingly made. Other births were noted as they occurred. For adult rats a file of dates of birth was available.

\section{Observations}

\section{Gestation Period}

The gestation period appears to lie within the range $21-28$ days. Time intervals observed between the exposure of the female to the male and parturition were most frequently within the range of 21-24 days although there were several occasions where longer periods up to 28 days were noted. This confirms the reports by ScHantz (1943), Hamilton (1946) and STEwARD (1951) who indicated that the rice rat family has a gestation period of similar duration. Breeding frequency in the colony was variable and it is known that the seasonal distribution of pregnancies in a wild population was bimodal, with the principle peak occuring in the late summer. Gravid Oryzomys have been noted by BRIMELY (1923) stretching from March to November, and this has been supported by Goldman (1918) who stated that "at all seasons is ample evidence that there is no breeding season, except possibly near the northern limit of the group". Within the colony i.e. laboratory environment, the normal seasonal conditions were considerably restricted, but a slight persistence towards the seasonal cycle was still present - possibly stimulated by the length of daylight.

\section{Litter Size and Sex Ratio}

Throughout the whole period of observation, only one litter of 10 survived the preweaning period. For the remainder, a number of litters consisting of $6-7$ rats were 
observed, a larger number of litters contained 3 young while the most common occurrence were litters containing $1-2$ rats. The mean litter size surviving to weaning was 3.6 rats per litter. Sex ratios within the litters, especially during the early phases when some died and were eaten, were difficult to assess accurately since interference of any kind invariably set off desertion or cannibalism. A predominance of numbers of any particular sex in the early phase is controlled by a number of variables, hence only those which survived could be used to give any indication. Within the surviving rice rats the total numbers of males and females appeared to be fairly even. 162 males and 155 females survived to weaning. The Chi-square test with correction for continuity shows that such distribution does not deviate significantly from 50:50 as P lies between .90 and .50 . Once a female rat was observed as being unable to rear her family satisfactorily, she was promptly removed from the breeding nucleus. Observation during the establishment of the colony showed that a small percentage of second-time mothers improved on their previous rearing performance and did not revert to cannibalism or desertion.

The general physical condition of any animal colony can be partly revealed by the state of fecundity and the ability of the young to be weaned and reach maturity. The success of the colony can therefore be measured from the general overall improvement of the growth of the rats in successive generations.

Table 1

\section{Analysis of Litters}

\begin{tabular}{|c|c|c|c|c|c|c|c|c|}
\hline \multirow[t]{2}{*}{$\begin{array}{l}\text { Breeding } \\
\text { Females }\end{array}$} & \multirow[t]{2}{*}{$\begin{array}{c}\text { No. of } \\
\text { Preg- } \\
\text { nancies }\end{array}$} & \multirow[t]{2}{*}{$\begin{array}{l}\text { Litters } \\
\text { Born }\end{array}$} & \multirow[t]{2}{*}{$\begin{array}{c}\text { Litters } \\
\text { Surviving } \\
\text { to Weaning }\end{array}$} & \multirow[t]{2}{*}{$\begin{array}{c}\text { Litter } \\
\text { Survival } \% \\
\text { to Weaning }\end{array}$} & \multirow[t]{2}{*}{$\begin{array}{l}\text { No. of } \\
\text { Young } \\
\text { Survived } \\
\text { to Weaning }\end{array}$} & \multicolumn{2}{|c|}{$\begin{array}{c}\text { No. of Young } \\
\text { per live } \\
\text { litter } \\
\text { Surviving } \\
\text { to Weaning }\end{array}$} & \multirow[t]{2}{*}{$\begin{array}{l}\text { No. of } \\
\text { Young per } \\
\text { live litters } \\
\text { Surviving } \\
\text { to Weaning } \\
\text { Mean }\end{array}$} \\
\hline & & & & & & Mean & Range & \\
\hline 49 & 1 & 49 & 28 & 57 & 71 & 2.54 & $1-5$ & 1.45 \\
\hline 35 & 2 & 35 & 24 & 69 & 118 & 4.92 & $2-10$ & 3,37 \\
\hline 25 & 3 & 25 & 17 & 68 & 61 & 3.59 & $1-6$ & 2.44 \\
\hline 15 & 4 & 15 & 10 & 67 & 35 & 3.50 & $1-5$ & 2.33 \\
\hline 8 & 5 & 8 & 4 & 50 & 18 & 4.50 & $4-6$ & 2.25 \\
\hline 6 & 6 & 6 & 3 & 50 & 9 & 3.00 & $1-5$ & 1.50 \\
\hline 4 & 7 & 4 & 1 & 25 & 4 & 4.00 & $-4-$ & 1.00 \\
\hline 4 & 8 & 4 & 1 & 25 & 1 & 1.00 & $-1-$ & 0.25 \\
\hline 2 & 9 & 2 & 0 & 0 & 0 & - & - & - \\
\hline 1 & 10 & 1 & 0 & 0 & 0 & , & - & - \\
\hline \multicolumn{9}{|c|}{$\begin{array}{l}1 \text { The number of females breeding were not constant for successive pregnancies since } \\
\text { some died of natural causes while others were removed after showing a poor breeding } \\
\text { capacity. }-2 \text { The heading "Litters Surviving..." indicates all the litters in which } \\
\text { one or more young rats lived to be weaned. }-3 \text { An exact total of all the young born } \\
\text { was not possible since the actual birth was rarely observed and a number of the young } \\
\text { were often eaten before a census was obtained. }\end{array}$} \\
\hline
\end{tabular}

In order to examine the development of the colony, all the records of the individual rice rats which had accumulated from the establishment of the colony in 1967 to the termination of the present work in 1971, were collected and inspected. Emerging from the data were two important points relevant to the problem - firstly the number of litters born to each female in the colony and secondly, the number of young rats which survived past the weaning stage. The findings are summarised in Table I. 


\section{Colony Census and Longevity}

The life span of rice rat under laboratory conditions is a difficult subject to study since there are high mortality rates in the young, the removal of individuals for experimental purposes and the usual culling which takes place to remove the old and infirm. The present observations have been based on the rats known to have died in their cages without any experimental interference. A total of 84 of these "natural" deaths were recorded excluding the numerous fatalities found in the young immature rats. These figures also ignore those animals dying during birth of their litters.

The results of the male rats after analysis showed a range of 1-33 months Table 2

Age Analysis of the Rice Rat Colony

(Months)

\begin{tabular}{|c|c|c|c|}
\hline & Male & Female & Combination \\
\hline $\bar{X}$ & 10.63 & 10.63 & 10.73 \\
\hline $\mathrm{S}^{2}$ & 48.91 & 45.64 & 30.60 \\
\hline S & 6.99 & 6.76 & 5.53 \\
\hline$S \bar{x}$ & 1.0664 & 1.0550 & 0.6035 \\
\hline $\mathrm{C} \%$ & 65.8 & 63.59 & 51.5 \\
\hline Range & $1-33$ & $1-24$ & $1-33$ \\
\hline \multicolumn{4}{|c|}{$t$ for the combined figures was found to be 0.0041} \\
\hline
\end{tabular}
while females showed a

range of 24 months. The following table shows the results of the age survey for 43 males and 41 females.

The cumulative frequency $\%$ curve derived from figures suggests that the males live longer than the females since the females die by 24 Months. In this respect it must be noted that only two of the males lived longer than 24 months -31 and 33 respectively - and that the rest follow a similar pattern to that of the females. Inspection of the frequency distribution curve show it to be PoIsson in outline with the long tail characteristic for population mortalities. On the bases of the calculations and plots it is clear that this mortality sample indicates a mean life of $101 / 2$ months.

\section{Morphological Development}

\section{Integument and Pelage}

The young rice rats were examined within 4 hours of birth and showed a red transparent skin, smooth in texture and in which numerous blood vessels were prominent. On close inspection of the skull, the cranial sutures could be seen while in the abdomen region the viscera could be seen through the outer wall. In some instances a darkish cast was visible on the head and part of the dorsum. The pinnae were folded over and sealed. Examination of the eyes showed that the dark iris was just visible through the lids. Mystacial vibrissae were present and were sufficient in number to demonstrate the pattern of rows later observed in the adult stages. Of the other vibrissae, the superciliary vibrissae was found to be erupting in some specimens. The lower and upper genals, the submental and inter-ramal were not present. A number of short bristles were evident on the lips and chin. Positions of most of the hair follicles over the dorsum were made visible by the deposition of pigment.

Changes visible by the first day included an increase in the amount of fine hair and the outline of the centrally-placed white spot on the forehead of many of the rice 
rats. Skin examination showed that it was definitely drier than at birth, less of the skull sutures could be seen although the viscera remained as before. The general pattern of hair distribution was now becoming evident since it had now spread over the dorsum with a few isolated hairs appearing on the sides and parts of the legs. Darker hairs were visible on the crown, nape and shoulders.

Two days after birth showed the outlines of the white spot developing on the forehead to be more clearly marked. The dorsum of the young rats had become darker and the central regions a little lighter. The dorsum had fairly long hairs which now extended down to the lower rump. The skin of the tail, at this point, showed no signs of hair eruption. The legs, on the other hand, had an increased distribution of hair and there were patches of pigment on the plantar surface of the pes.

Third day changes appeared to support a steady continuation of the previous pattern since the white spot on the forehead became a little more dense and the general pelage had thickened up with the results that the skull sutures were no longer visible. The hair of the dorsum now extended to the base of the tail which had a number of shorts hairs and a few scales on its surface. Examination of the plantar surfaces of the pes showed a further increase in pigment deposition. The upper and lower genal sensory perceptors of the vibrissal group were now erupting - generally the upper genals were longer.

Fourth day changes showed a departure from the fuzzy appearance which had so far dominated the dorsum region. This was now giving way to well formed hairs. The ventral pelage although having increased its hair density was still a little behind that of the dorsum. The darkish brown colouration of the general pelage was now clearly shown with the darker patches on the nape of the neck. Both manus and pes had a number of short hairs as also did the pinnae. In the tail region, the characteristic "scaly" tail was more evident and there was a greater abundance of hair. On the head, all the vibrissae were now present in varying degrees of eruption - the eruption of the submental and inter-ramal receptors having completed the full vibrissal pattern.

Hair growth on the manus and pes by the fifth day from birth showed little change compared to the previous day. The eyelids, however, showed a considerable growth of hair including signs of pigment deposition along the fusion line. The central region had a general increased hair density.

Over the next three days, little change was noted apart from a general thickening of the hair of the general pelage with particular emphasis on the ventral region. The eyes were noted at the end of this period ( 8 th day) to have signs of opening although there appeared to be a considerable range of variation. The legs throughout this period became fully covered with hair and by the tenth day the ventral aspect had completed its hair covering. Around this period, the female rat showed the development of eight pairs of mammae; in three instances supernumeraries were observed.

Initially, examination at birth showed the digits of the manus and pes to be together with rounded claws. During the four days following the mature shape of the claws emerged with the digits gradually separating.

In the majority of the rice rats examined during the first day after birth, the pinnae were found to have unfolded away from the head. The opening of the ears was found to be variable but in most instances the external auditory meatus was open on the seventh, eighth and ninth days. Reactions to sharp sounds proved to be inconclusive.

Opening of the eyes was observed to start around the eighth day and by the eleventh day the eyes of the majority of rats appeared to be functional. It is interesting to note that around this time the young rats were exhibiting a considerable amount of mobility. 
A further examination was made of the full mystacial vibrissal pattern in the older mature rats. Rows of receptors were found similar to those of the albino rat, grouped in five rows nearly parallel to the bridge of the nose. Each row had 4-7 easily identified large vibrissae. The caudal ones were long and thick. The vibrissae gradually diminished in both dimensions as they became located more rostrally. Four large vibrissae straddled the caudal ends of the five rows. Rostrally the diminution in size makes it difficult, on gross inspection, to be certain where the vibrissal rows stop, however, a few preliminary counts indicated that there were approximately 35 in the rice rat.

The growth of new hair and the molting cycle was not studied.

\section{Growth of the Body}

Examination of the data over the first 20 days of postnatal development showed that when regression lines were constructed on the means, that it was not possible to form meaningful curvilinear regression lines to the same formula as lines fitted by eye. This stemmed from the fact that these were of various shapes, broadly based on log growth curves. Confirmation of this is supported by Figures 1 and 2 which show lines constructed for mean weights and head-body lengths respectively.

Close examination of the curves fitted by eye superimposed on linear regression lines of the data of weight and head-body length appeared to follow the previous developmental pattern observed in albino rats (PARK 1969, PARK and NowOSIELSKISlepowron 1971). The similarity suggested that linear regression lines were suitable for construction for both sets of measurements. There was one significant point, however, that in most instances the line could be broken into three parts thus indicating three growth phases.

In order to achieve this aim, examination of the data indicated that the three lines for the rice rat would be best allocated within firstly; 4, 5 or 6 days; secondly, 11, 12

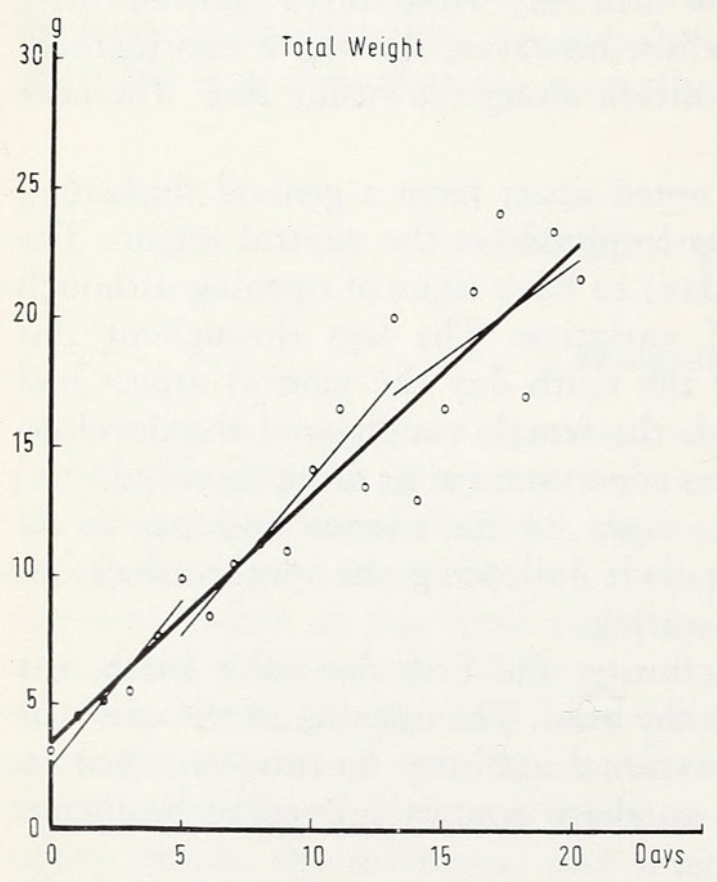

Fig. 1. Total and broken regression lines constructed from the means of combined males and females during the preweaning phase or 13 days; while the third occupied the remaining days to 20 . The final decision was made by use of the calculations of the regression lines of the various breakdowns of the total regression line based on the largest overall differences of the regression coefficient. With the data available at the present time, the tentative breakage points can be regarded as being formed by the groupings within $0-5$ days, 6-13 days and 14-20 days. Although this particular triphasic division requires further investigation it is obvious that there are three different rates of growth within the preweaning stage of development.

To investigate growth patterns following the first 20 days, the means of weight and head-body length were plotted on simple graph paper (Fig. 3). Two points emerged from the results, firstly that the differentiation of the sexes appeared after 20 days the weight differences showing before the head-body length. Secondly, examination 


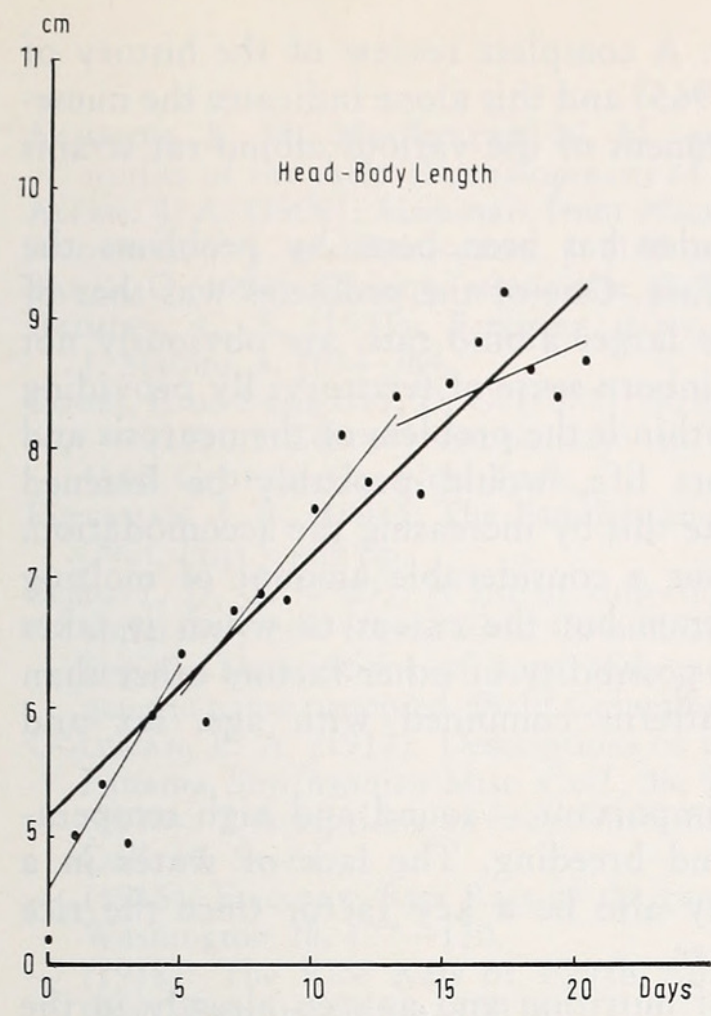

Fig. 2. Total and broken regression lines constructed from the means of combined males and females during the preweaning phase

of the older animals showed that weight and length of the males continues to grow while the females gradually slowed down. The latter, being derived from the detailed study which terminated at the 16th month, turned the investigation towards the colony as a whole and this revealed that the males showed a flattening of the curve around 20 months.

Sexual differences of the rats after 20 days were found to be gradual with the most obvious changes occurring in the weight. By 1 month the division between the sexes is well marked and through the greater increase of the males, continues to widen relatively until the females lessen in growth rate around 16 months while the males increase slows at 20 months. The final difference in weight was approximately 30-35 grams between male and female.

Curves of means of the head-body lengths showed sexual dimorphism after 20 days, but the differences in the measurements were not so marked as those on weight. As before, the males showed a steady increase which appeared to terminate around 16 months. The curve of the femal lagged behind the male, gradually flattening around 12 months. The difference between the sexes appeared to be of the order or $2.4 \mathrm{cms}$. Since the colony census did not provide length measurements, confirmation beyond 16 months was not possible.

\section{Discussion}

The transition of a wild rodent into a domesticated laboratory rat requires in most instances one important factor among others - namely time. In the present circumstances the original Harvard group of rice rats reached their 15 th generation before a daughter colony was established in Dundee. The albino rat, once introduced to the laboratory environment, appears to have adapted itself and with carefully planned breeding finally
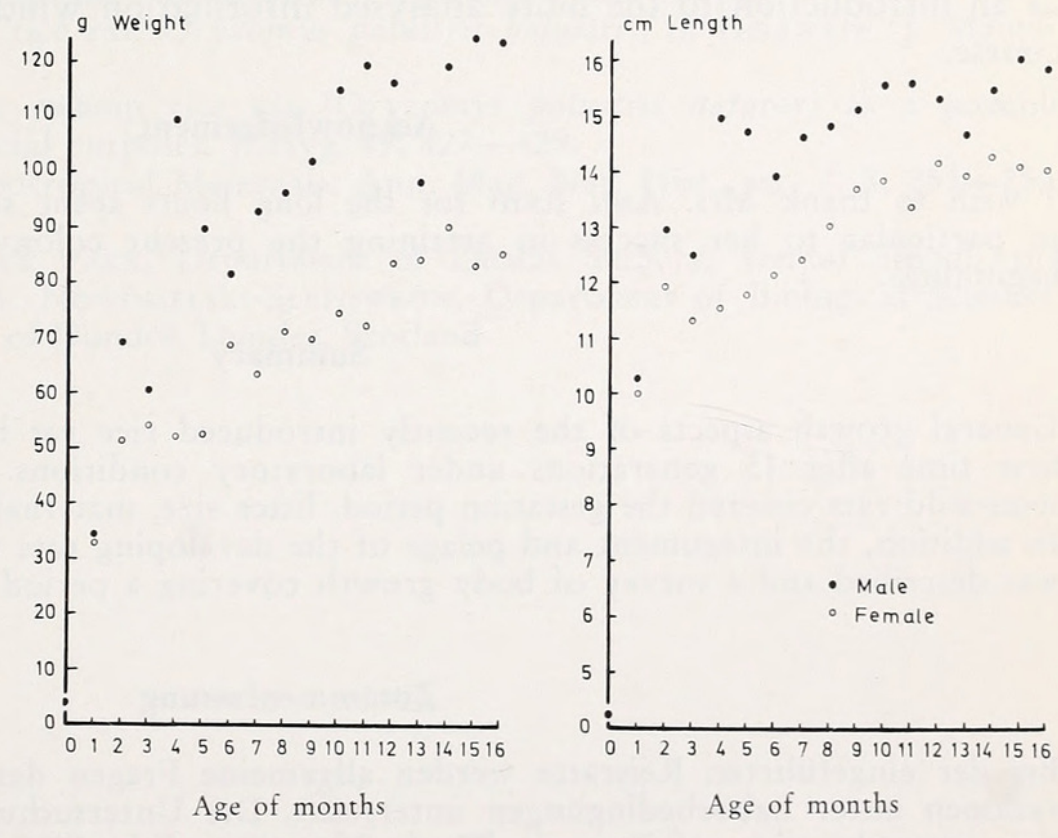

Fig. 3. Distribution chart of means of males and females covering weight and head-body length during the postweaning phase 
turned into the tractable animal known today. A complete review of the history of the albino rat has been covered by Robinson (1965) and this alone indicates the numerous problems which arose prior to the establishment of the various albino rat strains used today.

Establishment of a healthy colony in Dundee has been beset by problems the solving of which have hardly scratched the surface. One of the problems was that of space. The cages - which are acceptable by the larger albino rats, are obviously not suitable for animals which retain much of their inborn sense of territory. By providing a larger living space and keeping less animals within it the problem of the neurosis and related failure to breed, canniblism and short life, would probably be lessened considerably. Plans are being made to investigate this by increasing the accomodation.

The physical condition of the rats varies but a considerable amount of molting has been noted. Molting is a normal phenomenon but the extent to which it takes place on these rice rats leads one to suspect the possibility of other factors other than a seasonal cycle. Information of molting patterns combined with age, sex and condition are being studied at the present time.

External conditions have been found to be important - sound and high temperatures having detrimental affect on stability and breeding. The lack of water in a large enough volume to permit swimming may also be a key factor since the rice rats normally live in habitats which include water.

One of the most important factors is that of nutrition and as seen already in the text the particular diet provided is, in reality, one suitable for the albino rat. There is no evidence that this diet is sufficient for the needs of the rice rat colony and measurement of their needs will only come to light after a longer time under laboratory conditions. At present it cannot be said that adaption to nutrition arises from choice since the rice rat is being forced to adapt in toto to the conditions laid down. As in the previous problems, efforts are being made to vary the diet in order to raise the standard of the colony.

Finally, in attempting to give a survey of a newly annexed wild animal living under laboratory conditions, it is only possible to deal with some of the aspects of its development and life and the observations reported in this paper are only intended as an introduction to the more analysed information which will be published in due course.

\section{Acknowledgement}

I wish to thank Mrs. ANN ReID for the long hours spent supervising the rice rats and in particular to her success in attaining the present colony strength from very smali beginnings.

\section{Summary}

General growth aspects of the recently introduced rice rat have been examined for the first time after 15 generations under laboratory conditions. The investigation of these semi-wild rats covered the gestation period, litter size, maternal capacity and the longevity. In addition, the integument and pelage of the developing rats within the preweaning phase was described and a survey of body growth covering a period from birth to over 2 years.

\section{Zusammenfassung}

Bei der eingeführten Reisratte werden allgemeine Fragen des Wachstums nach 15 Generationen unter Laborbedingungen untersucht. Die Untersuchung dieser halbwilden Nagetiere erstreckte sich auf Tragzeit, Wurfgröße, mütterliche Fähigkeiten und die Lebensdauer. Außerdem wurden Haut und Haar der sich entwickelnden Tiere beschrieben, sowie eine Zusammenstellung des Körperwachstums von der Geburt bis zum Alter von 2 Jahren gegeben. 


\section{Literature}

Acheson, R. M., Macintyre, N. N., and Oldham, E. (1959): Techniques in longitudinal studies of the skeletal development of the rat. Brit. J. Nutr. 13, 283-292.

Allen, J. A. (1908): Mammals from Nicaragua. Bull. Amer. Mus. Nat. Hist. 24, 654-657.

Audubon, J. J., and Bachmann, J. (1854): The Quadrupeds of North America, 3, 214-216.

Bangs, O (1902): Chiriqui mammalia. Bull. Mus. Comp. Zool. 39, 33-36.

Brimley, C. S. (1923): Breeding dates of small mammals at Radleigh, North Carolina. J. Mamm. 4, 263-264.

Coues, E. and Elliott, D. G. (1877): Monogr. North American Rodentia 113-117.

-, - (1890): Century Dictionary: an encyclopaedic lexicon of the English language, 4, 4165. Century Co. New York.

Ellerman, J. R. (1941): The Families and Genera of Living Rodents, Vol. 1. British Museum (Nat. Hist.). 689 pp.

Elliott, D. G. (1903): A list of collection of Mexican mammals, with descriptions of some apparently new forms. Field Columbian Mus. Publ. 71. Zoological Series. 3, 145.

- (1904): Descriptions of apparently new species and subspecies of mammals and a new generic name proposed. Field Columbian Mus. Publ. 90. Zoological Series 3, 266-267.

Goldman, E. A. (1912): Descriptions of twelve new species and subspecies of mammals from Panama. Smithsonian Misc. Coll., 56, 5-8.

- (1913): Descriptions of new mammals from Panama and Mexico. Smithsonian Misc. Coll. 60, 5-6.

- (1915): Five new Rice Rats of the genus Oryzomys from Middle America. Proc. Bio. Soc. Washington 28, 127-130.

- (1918): The Rice Rats of North America. Nrth American Fauna No. 43. Washington Govt. Printing Office, $100 \mathrm{pp}$.

Gupta, O. P., and Shaw, J. H. (1956): Periodontal disease in the rice rat. O. Surg. O. Med. O. Path. 9, 592-603.

Hamilton, W. J. (1946): Habits of the swamp rice rat Oryzomys palustris palustris (Harlan). Amer. Mid. Nat. 36, 730-736.

Harlan, R. (1837): A description of a new species of quadruped of the order Rodentia inhabiting the United States. Amer. Jour. Sci. and Arts. 31, 385-386.

Merriam, C. H. (1901): Synopsis of the Rice Rat (Genus Oryzomys) of the United States and Mexico. Proc. Washington Acad. Sci. 3, 273-295.

PARK, A. W. (1969): Morphological aspects of sample selection during early postnatal cranio-fracial development. M.D.S. Thesis, Univ. Dundee. 358 pp.

Park, A. W., and Nowosielski-Slepowron, B. J. A. (1971): The effects of litter size on rat body growth. Acta. anat. 79, 15-26.

Robinson, R. (1956): Genetics of the Norway Rat. Pergamons Press. 804 pp.

Schantz, V. S. (1943): The rice rat, Oryzomys palustris palustris, in Delaware. J. Mamm. $24,103-104$.

STEWARD, J. S. (1951): The swamp rice rat (Oryzomys palustris natator) as a possible laboratory animal for special purposes. J. Hyg. 49, 427-429.

Thomas, O. (1901): New Neotropical Mammals. Ann. Mag. Nat. Hist., ser. 7. 8, 251-253.

Authors' Address: A. Wallace Park, Department of Dental Surgery, Dental School, and Dr. B. J. A. Nowosielski-Slepowron, Department of Biological Sciences, University of Dundee, Dundee, Scotland 


\section{$2 \mathrm{BHL}$ Biodiversity Heritage Library}

Park, A Wallace and Nowosielski-Slepowron, B J A . 1971. "Biology of the Rice Rat ( Oryzomys palustris natator) in a Laboratory Environment." Zeitschrift für Säugetierkunde : im Auftrage der Deutschen Gesellschaft für Säugetierkunde e.V 37, 42-51.

View This Item Online: https://www.biodiversitylibrary.org/item/161844

Permalink: https://www.biodiversitylibrary.org/partpdf/191225

\section{Holding Institution}

Smithsonian Libraries

\section{Sponsored by}

Biodiversity Heritage Library

\section{Copyright \& Reuse}

Copyright Status: In Copyright. Digitized with the permission of the rights holder.

License: http://creativecommons.org/licenses/by-nc-sa/3.0/

Rights: https://www.biodiversitylibrary.org/permissions/

This document was created from content at the Biodiversity Heritage Library, the world's largest open access digital library for biodiversity literature and archives. Visit BHL at https://www.biodiversitylibrary.org. 